\title{
Topology-optimized mode converter in a silicon-on-insulator photonic wire waveguide
}

\author{
Frellsen, Louise Floor; Ding, Yunhong; Sigmund, Ole; Frandsen, Lars Hagedorn
}

Published in:

CLEO: Science and Innovations 2016

Link to article, DOI:

10.1364/CLEO_SI.2016.STh3E.4

Publication date:

2016

Document Version

Peer reviewed version

Link back to DTU Orbit

Citation (APA):

Frellsen, L. F., Ding, Y., Sigmund, O., \& Frandsen, L. H. (2016). Topology-optimized mode converter in a siliconon-insulator photonic wire waveguide. In CLEO: Science and Innovations 2016 [STh3E.4] Optical Society of America (OSA). https://doi.org/10.1364/CLEO_SI.2016.STh3E.4

\section{General rights}

Copyright and moral rights for the publications made accessible in the public portal are retained by the authors and/or other copyright owners and it is a condition of accessing publications that users recognise and abide by the legal requirements associated with these rights.

- Users may download and print one copy of any publication from the public portal for the purpose of private study or research.

- You may not further distribute the material or use it for any profit-making activity or commercial gain

- You may freely distribute the URL identifying the publication in the public portal 


\title{
Topology-optimized mode converter in a silicon-on-insulator photonic wire waveguide
}

\author{
Louise F. Frellsen ${ }^{1, *}$, Yunhong Ding ${ }^{1}$, Ole Sigmund ${ }^{2}$, and Lars H. Frandsen ${ }^{1}$ \\ ${ }^{I}$ DTU Fotonik, Department of Photonics Engineering, Technical University of Denmark, 2800 Kgs. Lyngby, Denmark \\ ${ }^{2}$ DTU Mekanik, Department of Mechanical Engineering, Technical University of Denmark, 2800 Kgs. Lyngby, Denmark \\ "louifr@fotonik.dtu.dk
}

\begin{abstract}
A $1.4 \mu \mathrm{m} \times 3.4 \mu \mathrm{m}$ fundamental to first order mode converter for the transverse electric polarization was designed using topology optimization. Insertion loss $<2 \mathrm{~dB}$ (100 nm bandwidth) and extinction ratio $>9.5 \mathrm{~dB}$.

OCIS codes: (230.3120) Integrated optics devices; (130.1750) Components
\end{abstract}

\section{Introduction}

Mode division multiplexing (MDM) is one of the proposed methods for increasing on-chip data capacity in optical communications [1]. Mode converters are components essential to support the processing of MDM signals and several approaches has been taken to realize such devices [1,2].

Topology optimization (TO) is a powerful inverse design tool, that has previously been shown to deliver robust, compact designs for nanophotonic components exhibiting low loss and controllable bandwidth [3].

Here, we experimentally demonstrate a topology-optimized design for a compact, low-loss, and broad-band mode converter converting the transverse electric fundamental even mode $\left(\mathrm{TE}_{0}\right)$ to the first higher order odd mode $\left(\mathrm{TE}_{1}\right)$.

\section{Design and modelling}

Previous work in the group has shown that compact mode conversion can be achieved through interferometric designs [4]. Hence, the initial structure for the TO, shown in figure 1(a), was made to reflect previous designs including a splitting region in the center of the structure and a narrow $1.4 \mu \mathrm{m} \times 3.4 \mu \mathrm{m}$ design domain. The objective of the $\mathrm{TO}$ is to convert a $\mathrm{TE}_{0}$ mode excited at position $\mathrm{A}$ (yellow) to the $\mathrm{TE}_{1}$ mode at position $\mathrm{B}$ (green). This is achieved by iteratively changing the material distribution within the design domain (purple) until the objective is fulfilled. The TO algorithm was developed in house [5] and performs repeated 3D finite-difference timedomain (FDTD) calculations to find the solutions of the state, adjoint equations combined with mathematical programming-based sensitivity analysis, and design updates. The light source used in the TO was a Gaussian pulse with a spectral width of $\sim 280 \mathrm{~nm}$ (full-width half maximum) centered at $\sim 1580 \mathrm{~nm}$. The optimization was done using a mesh with a resolution of $40 \mathrm{~nm}$ and in order to end up with a 'black and white' design feasible for fabrication progressive filtering, with a size of $120 \mathrm{~nm}$, was used. The TO was made for a $340 \mathrm{~nm}$ thick silicon slab, $\varepsilon_{\mathrm{Si}}=11.68$ and is placed on top of a silica buffer layer with a permittivity of $\varepsilon_{\text {silica }}=2.085$ and having air above the structure while the boundary conditions are perfectly matched absorbing layers. The topology-optimized structures were restricted to be uniform in the vertical direction to ensure the feasibility of fabrication. The resulting topology-optimized design in presented in figure $1(\mathrm{~b})$.
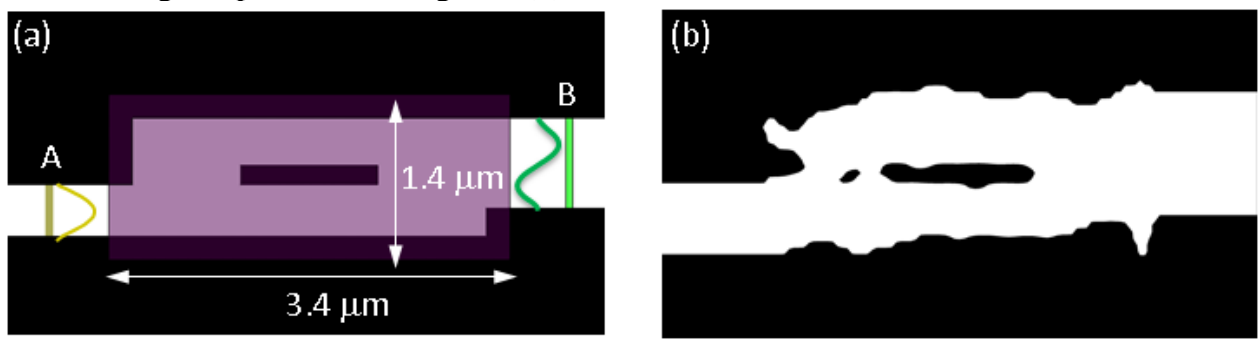

Figure 1 (a) The starting point structure for the optimization indicating source position (yellow) objective (green) and design domain (purple). The hole at the center of the structure was included based on knowledge from previous work. (b) The topology optimized design obtained after 200 iterations of optimization.

The performance of the structure was evaluated through simulations of the transmission, mode profile and visualization of the out-of-plane $\mathrm{H}$-field $\left(\mathrm{H}_{\mathrm{z}}\right)$, all shown in figure 2 . The theoretical insertion loss is found to be $<0.5 \mathrm{~dB}$ for a range of $100 \mathrm{~nm}$ and the design exhibits an extinction ratio of $\sim 14 \mathrm{~dB}$. 


\section{Experimental results}

The design was fabricated in an $\sim 340 \mathrm{~nm}$ silicon layer on top of an $2000 \mathrm{~nm}$ thick silica buffer layer. Using a JEOL JBX-9500 electron-beam lithography system the design was defined in a $\sim 110 \mathrm{~nm}$ thick layer positive electron beam resist (ZEP520A). The resist was used as a soft mask for inductively coupled plasma reactive ion etching using $\mathrm{SF}_{6}$ and $\mathrm{C}_{4} \mathrm{~F}_{4}$. Finally SU-8 polymer waveguides were added on inversely tapered silicon in- and output waveguides to optimize the coupling of light.

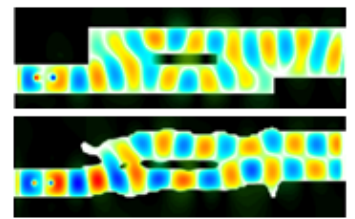

(a)

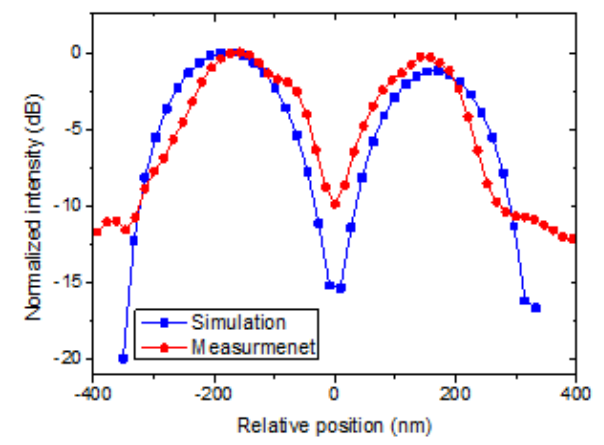

(c)

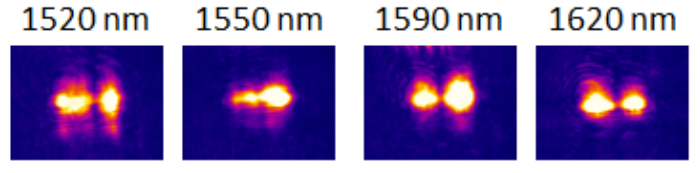

(b)

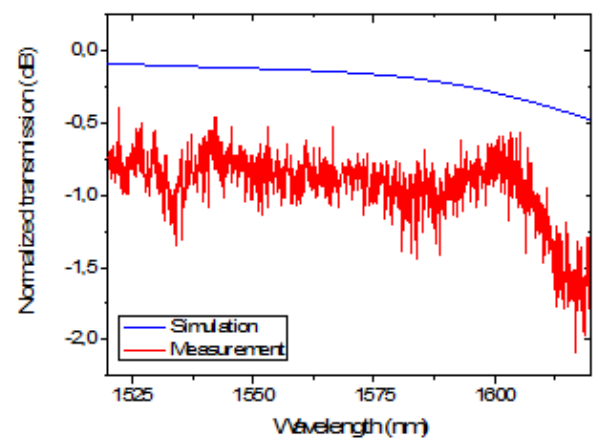

(d)

Figure 2 (a) $\mathrm{H}_{\mathrm{z}}$-field simulations for the initial structure (top) and topology optimized structure (bottom). (b) Recorded mode profiles from the range of $1520 \mathrm{~nm}$ to $1620 \mathrm{~nm}$. (c) Simulated and measured mode profile $1600 \mathrm{~nm}$. (d) Simulated and measured transmission of a single device, for easier comparison with the theoretical results.

The functionality of the device was experimentally verified by recording the mode profile of the converted signal with an InGaAs infrared camera (Xenics XEVA XC130). The measurements are shown in figure 2(b) along with a line scan across the mode profile, figure $2(\mathrm{c})$, revealing an extinction ratio of $>9.5 \mathrm{~dB}$ seemingly limited by the resolution of the setup.

The insertion loss of the design was determined by the measurement of light transmission converted first from $\mathrm{TE}_{0}$ to $\mathrm{TE}_{1}$ and then sent through a mirrored structure converting the light back to $\mathrm{TE}_{1}$ once more. As the device is reversible and characterized in the linear regime, the loss of a single device can be found by halving the values measured as has been done to the data presented in figure 2(d). The insertion loss is found to be $<1 \mathrm{~dB}$ for a range of $40 \mathrm{~nm}$ and to be $<2 \mathrm{~dB}$ for the entire $100 \mathrm{~nm}$ range of the laser.

\section{Conclusion}

Topology optimization was utilized to design a $\mathrm{TE}_{0}-\mathrm{TE}_{1}$ in a photonic wire waveguide with a compact footprint of $1.4 \mu \mathrm{m} \times 3.4 \mu \mathrm{m}$. The design was fabricated using e-beam lithography and functionality was experimentally verified. The transmission loss of the device was found to be $<2 \mathrm{~dB}$ for a $100 \mathrm{~nm}$ bandwidth and an extinction ratio of $>9.5 \mathrm{~dB}$ was exhibited.

\section{References}

[1] D. Ohana and U. Levy, "Mode conversion based on dielectric metamaterials in silicon," Optics express, 22, pp. 27617-27631 (2014).

[2] BT. Lee and SY. Shin, "Mode-order converter in a multimode waveguide" Opt. Lett, 28, pp. 1660-1662 (2003)

[3] J. S. Jensen and O. Sigmund, "Topology optimization for nano-photonics," Laser \& Photon Rev., pp. 308-321 (2011)

[4] L. F. Frellsen, L. H. Frandsen, Y. Ding, Y. Elesin, O. Sigmund and K. Yvind. ”Topology Optimixed Design for Silicon-on-Insulator Mode Converter", Proceedings for Ieee Photonics conference,pp. 162-163 (2015)

[5] Y. Elesin, B. S. Lazarov, J. S. Jensen and O. Sigmund, "Time domain topology optimization of 3D nanophotonic decives," Photon. Nanostruct. Fund. Appl., vol. 12, no. 1, pp. 23-33 (2014). 